\title{
Research on Application of Buckling Restrained Braces in Strengthening of Concrete Frame Structures
}

\author{
Niyonyungu Ferdinand ${ }^{\mathrm{a}^{*}}$, Zhao Jianchang ${ }^{\mathrm{b}}$, Yang Qiangqiang ${ }^{\mathrm{a}}$, Guobing Wang ${ }^{\mathrm{a}}, \mathrm{Xu}$ Junjie $^{\mathrm{a}}$ \\ ${ }^{a}$ School of Civil Engineering, Lanzhou Jiaotong University, Lanzhou, Gansu, China. \\ ${ }^{b}$ Professor, School of Civil Engineering, Lanzhou Jiaotong University, Lanzhou, Gansu, China.
}

Received 27 June 2019; Accepted 04 December 2019

\begin{abstract}
This paper examines the application of BRB in strengthening of reinforced concrete frame structures to meet seismic requirements according to Chinese seismic design code. Elastic response spectrum analysis and nonlinear time history analysis are performed by taking a real engineering example that suffers weak first floor irregularity due to added loads and addition of one floor. With the method of equivalent stiffness and displacement-based design method, buckling restrained brace parameters are deduced and are used to model BRB in ETABS using plastic wen model. Three configurations of buckling restrained braces are studied together with ordinary braces. Under elastic state, the relationship between the required cross section area of BRB and ordinary braces is deduced from the formula of calculating elastic bearing capacity where it is shown that the area of the ordinary braces must be 1.25 times that of BRB for ensuring the same performance. The results show that Inverted V brace configuration demonstrated better performance over single brace and $\mathrm{V}$ brace configurations and $\mathrm{X}$ brace configuration, although not recommended by Chinese code, is simulated and used in this paper and has demonstrated better performance over other configurations, and the further research on the practical use of this brace is recommended. Also, under action of strong earthquakes, by nonlinear time history analysis, buckling restrained braces demonstrated better performance of strengthening the structure and make it meet the requirement of code. Under this same condition, ordinary braces losses their bearing capacity due to excessive buckling.
\end{abstract}

Keywords: Buckling Restrained Brace; Flexible First Story; Response Spectrum; Nonlinear Time History Analysis; RC Frame Structure.

\section{Introduction}

Located between the Eurasian seismic belt and the circum-Pacific seismic belt, China is one of the countries with the largest number of earthquakes in the world and one of the countries with the greatest loss due to earthquake disasters because of its complex geological structure and frequent seismicity [1]. And with the steady development of Chinese cities vertically and horizontally, building codes are regularly revised to make sure that the safety is assured and meet the current status.

As the building codes become updated, some of the structures that have been designed by referring to the past codes do not meet the current standards and need to be rechecked and reinforced where needed. May researches have been done for mitigating earthquake disasters through improving seismic performance of buildings by incorporating energy dissipation dampers [2]. This was done to improve the seismic performance of moment frame structures that do not meet seismic requirements under sudden earthquakes.

\footnotetext{
* Corresponding author: niol20@yahoo.fr 
Central braces that have been a preferable method in increasing the lateral stiffness of the moment frames have low ability in energy dissipation due to buckling under compression and this make central braces not be able to achieve desired results [3].

In 1994, after Beijing earthquakes, engineers started to become hesitant in using central braces due to the failure of many building frames that were built by central braces. The research on ordinary central braces have shown that they can significantly improve the bearing capacity and lateral stiffness of frame structures but they cannot maintain the safety of frames under strong earthquakes, also because design of ordinary central frames is controlled by stability of compression bars, their slenderness ratio is very limited and this leads to large cross-section[4]. The big cross section increases the weight thus the seismic response of the structure is increased correspondingly and it can also affect the bearing capacity of the structure.

The research on the application of BRB in frame structures have shown that buckling restrained braces yield ductility in both compression and tension, they characterized by a full, stable and symmetric hysteretic loop with relatively low yield stiffness [5]. Although these two kinds of braces have been studied intensively in design of frame structures, their application in strengthening of reinforced frame structures against lateral and vertical loads is still not fully studied. There are many structures' circumstances that have not yet studied as far as using BRB in strengthening of reinforced frame structures. One of these circumstances is first weak story case that is used in this paper.

Taking the Flue Gas Desulfurization System engineering of Manzhou (2X200MW) Thermal Power Project building of Manzhou city in China as engineering case, based on ETABS finite element software, the response spectrum analysis according to Chinese code of seismic analysis of building structures and the nonlinear time history analysis under multiple earthquakes are carried out to understand the seismic performance of reinforced concrete frame structure strengthened by buckling restrained braces .In this paper, also the two the difference between buckling restrained braces and ordinary braces is highlighted.

It is common in engineering that some additional floor or loads that were not considered during analysis and design can be added to the buildings after construction. That additional load on the building increases mass of the super structure and this results in increase of seismic reaction of the structure and the vertical load, which will also affect the vertical load bearing system of the structure. Also, the seismic capacity of the structure that have been built before updating the codes cannot be considered to be safe without checking it against updated codes. It is very important to strengthen the existing building structures that do not conform to the current codes because significant human and economic losses have occurred in earthquakes $[6,7]$ and many countries cannot afford to demolish and build new structures

Buckling restrained braces have been proven efficient in increasing the seismic stiffness of the structure because of their full hysteretic curves [8, 9]. Results from the experiments conducted by Mazzolani et al. [10], on retrofitting of damaged structures showed that the seismic performance of steel structures can be improved by both buckling restrained(BRB) braces and eccentric braces, but the first provided larger displacement capacity and they proved that with BRB the increase in stiffness and strength can be better controlled. Kassai et al. [11], by using shaking table, conducted an experiment on a full scale five story steel frame structure with four different energy dissipation devices where BRB was among them; the frame structure was subjected to low intensity white noise and Takatori motion of the 1995 Kobe earthquake scaled to different intensity levels and the seismic performance results of the structures without and with these devices installed on four of five stories were compared where reduction in displacements, floor accelerations and story shears were reported on structures with BRB.

Hector et al [12] studied the effect of BRB on reinforced concrete precast structures, using shaking table experiments and the results showed that inclusion of BRB increased shear capacity, damping and fundamental natural frequency and reduced interstory drift and lateral displacement when subjected to low intensity and high intensity ground motions.

Significant increase in strength, deformation and energy dissipation capacity of reinforced concrete building structures due to inclusion of BRB was also confirmed by Andre Almeida et al. [13] in their research conducted by taking pre-code building structure. These are seismic characteristics that are important in limiting damage in the original structural elements.

The following gaps have been found from literatures:

First, most of the researchers have been focused on the application of BRB in design of new buildings. Therefore, there is a need to strengthen the research on the application of BRB in strengthening of existing structures.

Second, while in China, most of the buildings are reinforced concrete, researches on BRB are mostly applied in steel structures, therefore is beneficial to do research on the reinforced concrete structures as well.

Third, being very new, the research on the effect buckling restrained brace on the vertical and horizontal irregularity of frame structures has not been exhausted. This paper investigates the use of Buckling Restrained braces in strengthening flexible first story building due to added machine load and one floor that was not considered during design and construction stage. 
The methodology used in this paper is summarized in the Figure 1:

Diagnosis of the structure by Response spectrum Analysis according to GB500112010(Vibration analysis, rigidity analysis and displacement analysis) and determination of reinforcement requirements.


Figure 1. Flowchart of the research methodology

\section{Theoretical Analysis of Buckling Restrained Braces}

\subsection{Equivalent Stiffness of Buckling Restrained Braces}

\section{Elastic Stiffness}

Buckling restrained braces is an assembly of three components (Figure 2). Those are yielding steel bar, encasing material and restraining tube. But also, longitudinally, it has three sections: working section, transition section and connection section.



Figure 2. A typical Buckling restrained brace

By principles of mechanics of materials, the stiffness of each component can be obtained and the equivalent stiffness can be deduced. Assuming that the brace remains in elastic range;

Displacement of working section is calculated by Equation 1 as follows:

$\Delta l_{1}=\int_{l_{1}} \frac{p d x}{E A_{1}}=\frac{p l_{1}}{E A_{1}}$

And from Hooke's law, the corresponding elastic stiffness is calculated from Equation 2:

$K_{1}=\frac{P}{\Delta l_{1}}=\frac{E A_{1}}{l_{1}}$

For transition section, displacement is calculated by Equation 3:

$\Delta l_{2}=\int \frac{p d x}{E A_{2}}=\frac{P l_{2}}{E\left(A_{1}-A_{3}\right)}\left(\ln A_{1}-\ln A_{3}\right)$ 
And the elastic stiffness can be calculated by Equation 4:

$$
K_{2}=\frac{p}{\Delta l_{2}}=\frac{E\left(A_{1}-A_{3}\right)}{l_{2}\left(\ln A_{1}-\ln A_{3}\right)}
$$

Or:

$K_{2}=\frac{E A_{2}}{l_{2}}$

And the connection section, displacement is calculated by Equation 5:

$\Delta l_{3}=\int \frac{p d x}{E A_{3}}=g \frac{F_{N} l_{3}}{E A_{3}}$

And the corresponding stiffness is deduced by Equation 6:

$K_{3}=\frac{p}{\Delta l_{3}}=\frac{E A_{3}}{l_{3}}$

The equivalent stiffness of Buckling restrained brace can be calculated by the principle of stiffness of elements in series by Equation 7:

$K_{e}=\frac{1}{\frac{1}{K_{1}}+2 \frac{1}{K_{2}}+2 \frac{1}{K_{3}}}=\frac{E A_{1} A_{2} A_{3}}{l_{1} A_{1} A_{3}+2 l_{2} A_{1} A_{3}+2 l_{3} A_{1} A_{3}}$

Where; $\mathrm{P}$ is the axial load on BRB core member; $\mathrm{E}$ is the elastic stiffness;

$l_{1}, l_{2}, l_{3}$ length of working section, transition section and connection section respectively;

$\Delta l_{1}, \Delta l_{2}, \Delta l_{3}$ axial deformation of working section, transition section and connection section;

$A_{1}, A_{2}, A_{3}$ Cross sectional area of working section, transition section and connection section;

$K_{1}, K_{2}, K_{3}$ Elastic stiffness of working section, transition section and connection section;

$K_{e}$ Equivalent stiffness.

\section{Plastic stiffness}

For better energy dissipation effect, in nonlinear stage, the working section will be yielded before transition and connection section [14]. This is achieved by providing larger transition and connection section area than working section so that they remain elastic. The elastic modulus of working section will be change by, $E_{1}=\propto E$ where $\propto$ is the factor of inelasticity. The equivalent stiffness will be expressed as Equation 8:

$K_{e}=\frac{1}{\frac{l_{1}}{\propto A_{1} E}+2 \frac{l_{2}}{E A_{2}}+2 \frac{l_{3}}{E A_{3}}}$

\subsection{Stability Analysis of Buckling Restrained Braces}

\section{Global Stability Analysis of Buckling Restrained Braces}

Working basis of BRB is based on the fact that the restraining part will block the core section from buckling. If the restraining material is not strong enough, it will buckle together with the core and this will affect the global stability of the brace.

The ultimate strength (critical load $P_{C r}$ ) of BRB can be calculated from the Equation 12 deduced from Equations 9, 10 and 11 by assuming that the force is directly applied to core member as shown in Figure 3 and the friction between core member and restraining material is negligible [8] which means the force is transversally distributed and no longitudinal interaction.


Figure 3. BRB free body diagram 


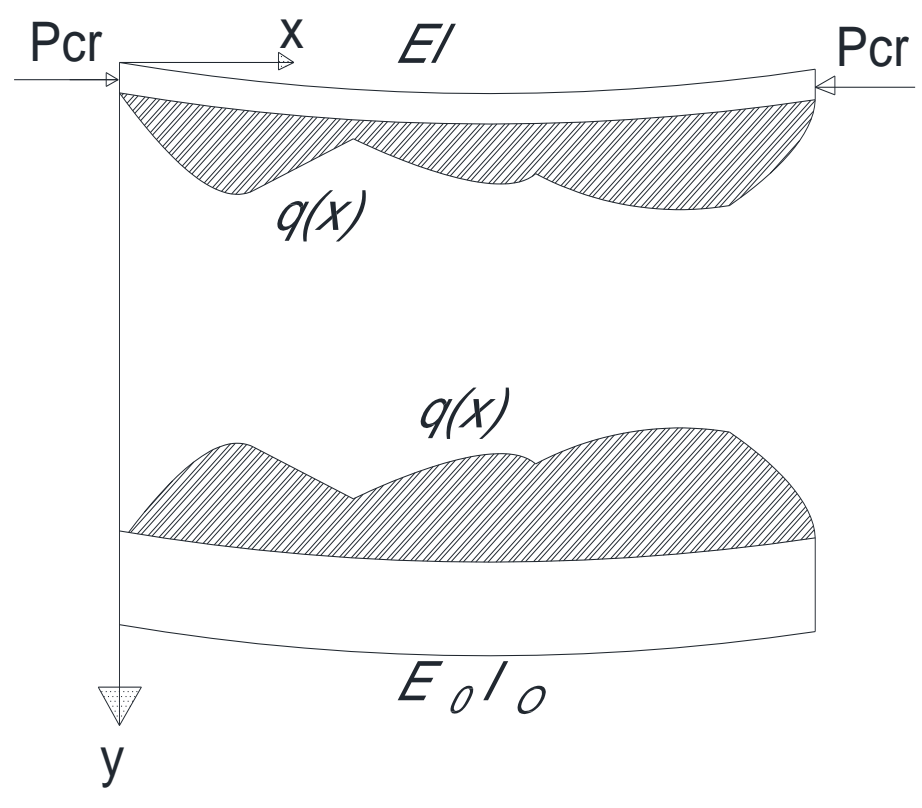

Figure 4. Isolated core and encasing body free body diagram of BRB

Equivalent equilibrium equation from free body diagram of Figures 3 and 4 is expressed by Equations 9 and 10 as:

$E_{1} I_{1} \frac{d^{4} y}{d x^{4}}+P \frac{d^{2} y}{d x^{2}}=-q(x)$

$E_{2} I_{2} \frac{d^{4} y}{d x^{4}}=q(x)$

Where;

$x$ and $y$ are axial and lateral displacement of BRB's core component;

$E_{1}, E_{2}$ Elastic modulus of core component and restraining material respectfully;

$I_{1}, I_{2}$ moment of inertia of core component and restraining material respectfully;

By combining (9) and (10), $\mathrm{q}(\mathrm{x})$ will be eliminated and Equation 11 will be deduced.

$\frac{d^{4} y}{d x^{4}}+\frac{P}{E_{1} I_{1}+E_{2} I_{2}} \frac{d^{2} y}{d x^{2}}=0$

By introducing the boundary conditions at both ends and solving the Equation 11, the critical load of the overall stability can be obtained by taking the length of the restraining section and core as one.

$P_{C r, g}=\frac{\pi^{2}\left(E_{1} I_{1}+E_{2} I_{2}\right)}{(\mu l)^{2}}$

$\mu$ is the effective length coefficient.

The ultimate bearing capacity of the brace will be: $P_{C r}=\frac{\pi^{2}\left(E_{1} I_{1}+E_{0} I_{0}\right)}{(\mu l)^{2}}$.

\section{Elastic-plastic Buckling Analysis of Brace Core Element}

The working principle for buckling restrained brace is that the load will be applied to the core material. When the load reaches the ultimate load, the restraining tube will restrain the core from excessive buckling.

Under strong earthquakes, if the overall bearing capacity of the brace is higher than the buckling load $F_{t}$ of the core section, the core will yield under compression before the overall instability occurs:

$P_{C r}=\frac{\pi^{2}\left(E_{1} I_{1}+E_{0} I_{0}\right)}{(\mu l)^{2}} \geq F_{t}$

$\mu$ is the length coefficient by considering the restraint conditions at the end of the brace. It's value ranges between 0.7 and 1,1 is considered in this paper.

\subsection{Analysis of Effect of BRB on the Stiffness of Frame Structure by Displacement-Based Method}

By considering single bracing frame shown in the Figure 5, the relation between the stiffness of the frame and that of the frame can be derived as follows: 


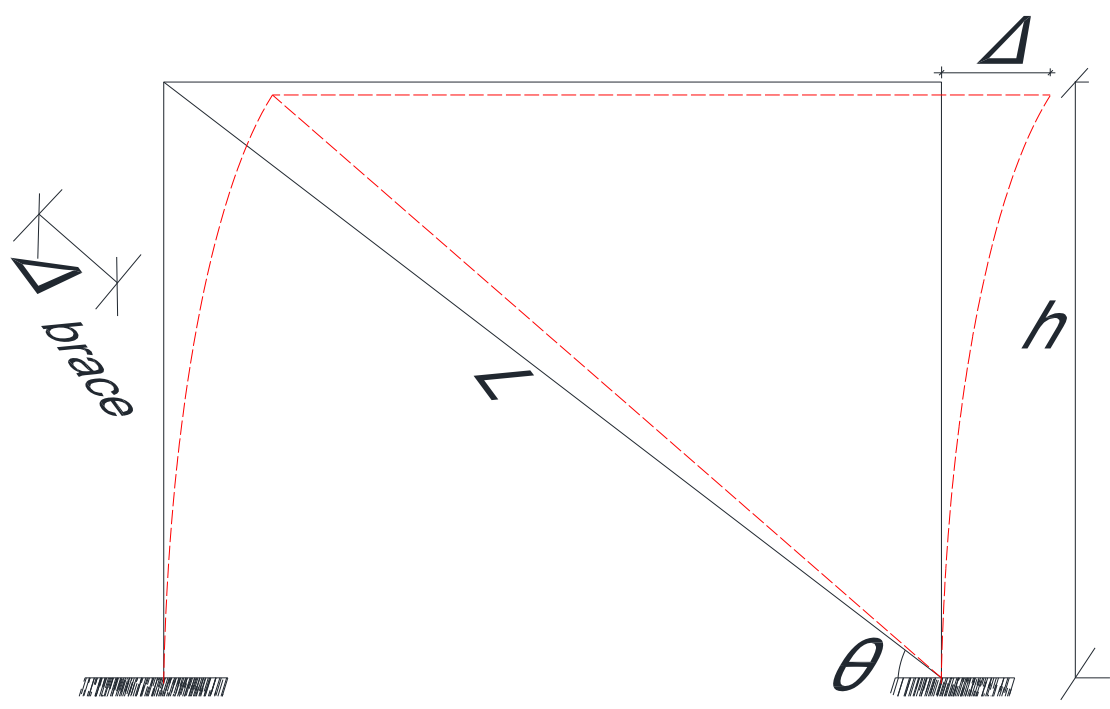

Figure 5. Relationship between displacement of brace and that of floor

The brace dimension for strengthening is deduced from displacement-based design of frame structures where, the displacement of the brace can be deduced geometrically from Figure 5 as the Equation 13 below:

$\Delta_{\text {Brace }}=\Delta \cos \theta$

And by Equation 14 the axial force of the brace is related to the displacement by Hooke's law as:

$F=\frac{E A}{L} \Delta_{\text {Brace }}$

Therefore, the horizontal stiffness of the brace support is $K_{\text {Brace }}=\frac{E A}{h} \sin \theta(\cos \theta)^{2}$.

For brace with two members the horizontal stiffness will be twice that of single brace, Equation 15:

$K_{\text {Brace }}=2 \frac{E A}{h} \sin \theta(\cos \theta)^{2}$

In this paper, the stiffness of the brace is computed by giving a target displacement that conform to the maximum elastic drift ratio and from that, all other parameters of the brace are deduced.

\section{Analysis of Buckling Restrained Brace Parameters}

In this paper Chinese codes are used as reference and the parameters of the BRB used in this paper have been analyzed and designed according to Chinese standard. The following are different parameters used:

\subsection{Model}

Bouc-Wen is a commonly used mechanical model for buckling restrained braces. The following is a brief introduction to the Bouc-Wen model $[15,16]$ used in this paper: The Bouc-Wen model can be described by Equation 16:

$\mathrm{F}(\mathrm{x}, \mathrm{z})=\gamma \mathrm{ku}+(1-\gamma) \mathrm{kz}$

Where, $\dot{Z}=\mathrm{A} \dot{X}-\alpha|\ddot{X}||Z||Z|^{n-1}-\beta \dddot{X}|Z|^{n} ; \mathrm{X}, \ddot{X}, \dddot{X}$ are displacement, velocity and acceleration.u(t):External influence; $\mathrm{z}$ : Bouc-Wen hysteretic nonlinear restoring force. And $A, n, \alpha, \beta$ : are hysteretic constants, and the properties of hysteretic nonlinear restoring force $\mathrm{Z}$ which depend on material properties, response amplitudes and structural properties.

In the ETABS software, the default $A=1, \alpha=\beta=0.5$, and the larger the value of the exponent $n$ is, the steeper the yield ratio is. If the $n$ value is infinite, the Wen model is close to the bilinear model, but this may overestimate the energy consuming capacity of the damper. Therefore, $\mathrm{n}$ is chosen between 1 and 20 according to the hysteretic characteristics of components

In this paper, Bouc-wen model is used as representative of Buckling restrained brace and its parameters are calculated from the material and geometrical characteristics of the braces used.

\subsection{Bearing Capacity of Buckling Restrained Brace}

In the seismic design, the axial bearing capacity design value of the buckling restraint support is determined according to Chinese code by Equation 17 from which yield and ultimate bearing capacity can be deduced to get representative Equations 18 and 19 respectively. 
$N_{b}=0.9 A_{1} f_{y}$

$A_{1}$ Cross section area of yielding core;

$f_{y}$ Yield strength value of core element material;

Yield bearing capacity is expressed as: $N_{b y}=n_{y} A_{1} f_{y}$.

$n_{y}$ : Yield strength coefficient of core element material.

The ultimate bearing capacity which is used for designing joints is calculated by: $N_{b u}=\omega N_{b y}$

$\omega$ Strain hardening adjustment factor for core element material.

The yield strength coefficient and strain hardening adjustment factor for core element materials are dependent on the material type of the core element. Table (1) represents example of commonly used core element in buckling restrained braces and their respective characteristics.

Table 1. Table yield strength, Yield strength coefficient and Strain hardening adjustment factor

\begin{tabular}{cccc}
\hline Material & $\boldsymbol{f}_{\boldsymbol{y}}(\mathbf{M P a})$ & $\boldsymbol{n}_{\boldsymbol{y}}$ & $\boldsymbol{\omega}$ \\
\hline Q100LY & 80 & 1.25 & 2.4 \\
Q160LY & 140 & 1.15 & 2.4 \\
Q235 & 235 & 1.15 & 1.5 \\
Q345 & 345 & 1.1 & 1.5 \\
\hline
\end{tabular}

\subsection{Equivalent Cross Section Area of Buckling Restrained Brace}

In reality, buckling restrained brace is an assemblage of different parts longitudinally and transversally. Longitudinally, it is divided into connection zone, transition zone and yielding zone. The cross-section areas of these different zones are different and it is very complicated to consider them as different areas during simulation. Also, transversally, the BRB has core, the restraining material. In design, the equivalent cross section area of the BRB is computed by using the Table 2 which gives the relationship between the length of the brace, cross section area of the core brace and the equivalent cross section area.

Table 2. Relation between cross section area $A_{1}$ of core element and equivalent area $A_{e}$

\begin{tabular}{cc}
\hline Length of BRB & $\boldsymbol{A}_{\mathbf{1}} / \boldsymbol{A}_{\boldsymbol{e}}$ \\
\hline $\mathrm{L} \leq \mathbf{3}$ & 0.85 \\
$\mathrm{~L}=\mathbf{6}$ & 0.9 \\
$\mathrm{~L}=\mathbf{9}$ & 0.95 \\
$\mathrm{~L} \geq \mathbf{3}$ & 0.99 \\
\hline
\end{tabular}

Relation between cross section area $A_{1}$ of core element and equivalent area $A_{e}$ of Buckling Restrained Brace according to buckling restrained brace manual fourth edition of Tongji University.

\subsection{Bending Stiffness Requirement of Encasing Element}

In order to ensure that buckling restrained braces do not affect overall instability under earthquake, the flexural stiffness of encasing elements should meet the following requirements (Table 3) according to buckling restrained brace manual fourth edition of Tongji University. In this paper, energy dissipation BRB are used:

Table 3. Relation between BRB type and encasing material stiffness

\begin{tabular}{cc}
\hline BRB Type & Encasing material stiffness requirement \\
\hline Load Bearing BRB & $\frac{\pi^{2} E I}{l^{2}} \geq 1.2 N_{b y}$ \\
Energy dissipation BRB & $\frac{\pi^{2} E I}{l^{2}} \geq 1.2 N_{b u}$ \\
\hline
\end{tabular}

$E$ : Elastic modulus of encasing material,

$I$ : Weak axis moment of inertia of encasing material,

$l$ : Length of BRB,

$N_{b u}$ : Ultimate bearing capacity of BRB,

$N_{b y}$ : Yield bearing capacity of BRB. 


\section{Real Engineering Case Study}

\subsection{Description of Engineering Model}

A three-story reinforced concrete frame building (Figure 6) with 16.5 meters height, built in 2008 is used as the model example for this paper. The building was designed according to Chinese codes. After construction, a heavy machine that has not been considered during analysis and design stage was installed to the rooftop and another floor is added to cover the machine, so this called for rechecking and strengthening of the original structure against additional loads.

The building is located in seismic fortification intensity of 7 and seismic acceleration of $0.1 \mathrm{~g}$ and structural design service life of the building is 50 years. The building has columns and beams with different dimensions with largest columns of $700 \times 700 \mathrm{~mm}$ and largest beam of $350 \times 950 \mathrm{~mm}$, the slab has dimension of $200 \mathrm{~mm}$. all the dimensions from engineering drawings are respected in modeling of the structure all with concrete of C30.



Figure 6. Engineering Model (ETABs)

\subsection{Structural Diagnosis of Engineering Model}

By response spectrum analysis of the engineering model, the maximum displacement, maximum drifts and frame stiffness are computed using ETABS software [17]. Three modal shapes that are translation in X direction (Figure 7.a), translation Y direction (Figure 7.b) and rotation (Figure 7.c) show that the maximum displacement is on the last floor.

Weak areas are obtained by comparing results with Code for Seismic Design of Buildings" GB50011-2010 that stipulates that the maximum drift ratio must be less than 1/550, the maximum period ratio (ratio of the third mode period to the first mode period) must be less than 0.9 and the story stiffness of the floor must not be less than the maximum of $70 \%$ of the upper floor stiffness and $80 \%$ of the average of all above floors). The modal results (Table 4, Figure 7) shows that the building meets the vibration requirements according to the code.

Table 4. Fist three Modal Periods

\begin{tabular}{cc}
\hline Mode & Period(seconds) \\
\hline 1 & 0.866 \\
2 & 0.748 \\
3 & 0.7 \\
\hline
\end{tabular}

The period ratio of the structure is 0.8 and meets the vibration requirements. The story displacement results (Table 5), maximum story drift (Table 6) and the story stiffness (Table 7) are shown below.

Table 5. Story displacement

\begin{tabular}{ccccc}
\hline Story & Elevation $(\mathbf{m})$ & Location & X-Dir $(\mathbf{m m})$ & Y-Dir $(\mathbf{m m})$ \\
\hline Story4 & 16.5 & Top & 19.185 & 15.041 \\
Story3 & 12 & Top & 16.62 & 13.066 \\
Story2 & 9 & Top & 12.671 & 10.851 \\
Story1 & 5.8 & Top & 9.569 & 7.365 \\
Base & 0 & Top & 0 & 0 \\
\hline
\end{tabular}


Table 6. Maximum story drift

\begin{tabular}{cccc}
\hline Story & X-Dir & Y-Dir & \\
\hline & & & GB50011-2010 \\
Story4 & 0.000585 & 0.000535 & CONFORM \\
Story3 & 0.001848 & 0.001427 & NOT CONFORM \\
Story2 & 0.001788 & 0.001349 & CONFORM \\
Story1 & 0.001514 & 0.00127 & CONFORM \\
Base & 0 & 0 & \\
\hline
\end{tabular}

Table 7. Frame Stiffness

\begin{tabular}{cccc}
\hline Story & X-Dir $(\boldsymbol{k} \boldsymbol{N} / \boldsymbol{m})$ & Y-Dir $(\boldsymbol{k} \boldsymbol{N} / \boldsymbol{m})$ & GB50011-2010 \\
\hline Story4 & 350845.3 & 453212.6 & conform \\
Story3 & 325892.7 & 456531.2 & conform \\
Story2 & 340911.1 & 473235.4 & conform \\
Story1 & 222887.3 & 311615.6 & Weak first story \\
Base & 0 & 0 & \\
\hline
\end{tabular}



(a)



(b)



(b)

Figure 7. First, second and third mode of vibration respectively

According to elastic response spectrum analysis results, it is found that the frame structure will suffer from weak first story which lead to concentrated deformation to the first story with the horizontal stiffness that does not conform to the Chinese standard GB50011-2010. This is due to the fact that the first story does not have sufficient lateral bearing elements because of the intended use of the structure. 
Also, the third story does not conform to the requirement of elastic story drift by the standard and this will make the building fail before entering to elastic plastic stage. This is due to the additional load and one story that caused the additional of the total mass of the building.

Therefore, it is necessary to reinforce the frame structure to improve the stiffness of the flexible floor and reduce the lateral displacement of the structure.

\subsection{Reinforcement Scheme}

\section{Location of BRB}

The braces must be arranged where they will solve the reinforcement objective without affecting the building function, stability and comfort of the users. The arrangement of BRB is done by the following three principles:

1. Where there is greater displacement and the resulting internal forces are greater, but without destroying the regularity of the original structure.

2. Where they will be insurance of the maximum possible symmetricity of the whole building and the stiffness center must coincide with mass center as much as possible to avoid torsion effect.

Because the earthquake loads are transmitted from the ground to the upper floors and its intensity is higher to the bottom than the top, reinforcing the bottom with energy dissipation devices will reduce the seismic energy transmitted to the upper floor of the building.

Also, when the reinforcement of the floor other than the first is needed (Third floor for this paper), braces should be arranged continuously from the bottom to the story where reinforcement is needed.



Figure 8. First floor layout with joint labels

From the analysis results it is found that grater internal forces and displacement are located on the external joints in $\mathrm{X}$ and $\mathrm{Y}$ directions, therefore BRB are proposed to be located between external columns (Figure 9.b).

Because the stiffness of the first floor in all directions does not conform to the standards, braces are symmetrically proposed in all directions of the first floor (Figure 9.a).

For the third floor, braces are installed where there is maximum displacement at the same time avoiding vertical and torsional irregularity (Figure 9.b).

In order to respect the vertical regularity, the reinforcement of the third floor are provided at the second floor too (Figure 9.b) and in order to conserve the torsional regularity, all the braces are placed symmetrically with respect to $\mathrm{X}$ and $\mathrm{Y}$ directions. 

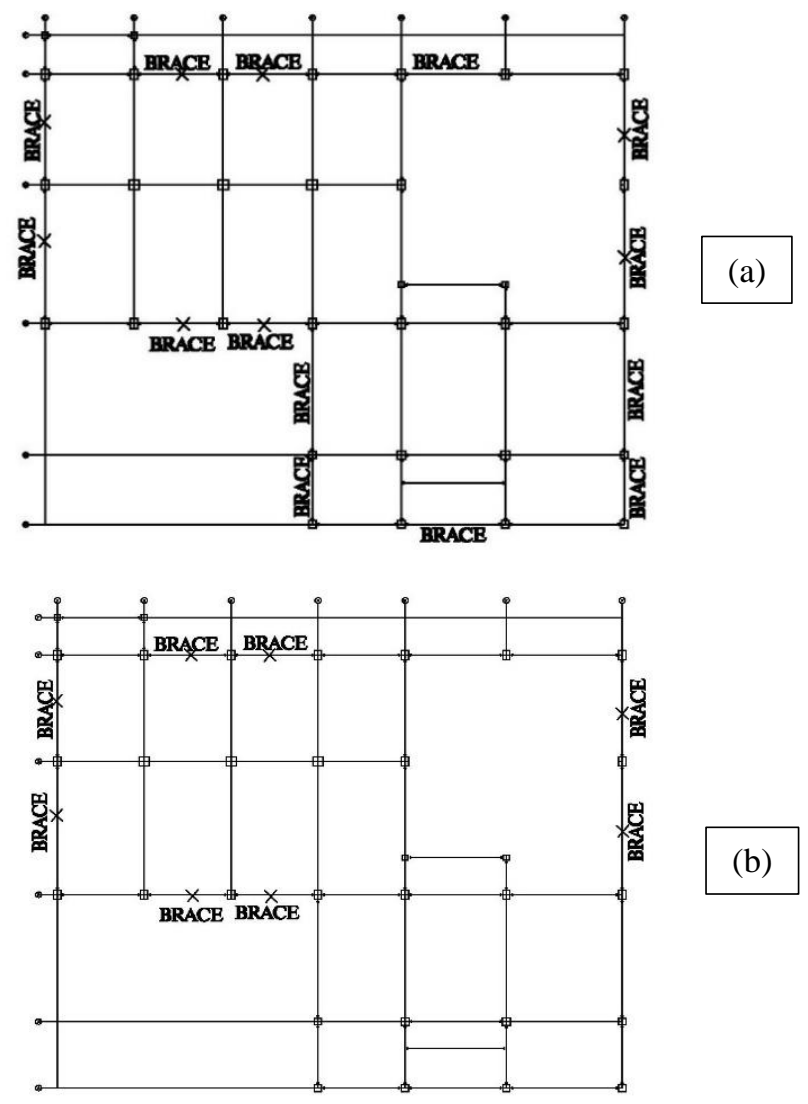

Figure 9. First (a) and Second (third) (b) floors reinforcement scheme layout.

\section{BRB Configurations}

In this paper, four different brace configurations were used, those are two chevrons ( $\mathrm{V}$ and Inverted $\mathrm{V}), \mathrm{X}$ configuration and Single brace.

\section{BRB Parameters}

In this paper, the buckling restrained brace has been simulated using ETABS 2017 and their length defined by frame dimension. Energy dissipation BRB was chosen for this paper and authors used Q235 as core material. The length of the brace was defined by the size of the other frame members where it was to be installed. By giving the first floor a maximum target displacement of $10.54 \mathrm{~mm}$ to conform to the standard of maximum drift ratio of $1 / 550$, the displacement of the brace is computed as $7.4529 \mathrm{~mm}$. In this paper, Q235 is used as core material for brace element and by using Tables 1 and 2, equivalence areas of the braces used are computed and presented in Table 8 .

Table 8. BRB parameters

\begin{tabular}{cccc}
\hline Brace & Equivalent Area $\left(\mathbf{c m}^{\mathbf{2}}\right)$ & Material & Type \\
\hline 1 & 153.16 & Q235 & Energy dissipation \\
2 & 68.67 & Q235 & Energy dissipation \\
3 & 53.1 & Q235 & Energy dissipation \\
\hline
\end{tabular}

\subsection{Analysis Results of Strengthened Engineering Model}

The strengthened building was analyzed by response spectrum analysis under the same loading conditions as the original frame, and the following response characteristics are obtained.

\section{Modal Analysis}

Table 9. Periods of first three modes of strengthened frame schemes (in seconds)

\begin{tabular}{cccc}
\hline Model & SINGLE BRB & X BRB frame & INVERTED V BRB Frame \\
\hline 1 & 0.498 & 0.415 & 0.48 \\
2 & 0.468 & 0.401 & 0.438 \\
3 & 0.356 & 0.3 & 0.33 \\
\hline
\end{tabular}


It can be seen from the Table 9 that there is a continuous vibration of the structure for both models including strengthened and original frames. However, the vibration period of single brace scheme is larger than other schemes.

\section{Rigidity Analysis}

It can be seen from the below graphs (Figure 10) that the overall stiffness of the structure strengthened by BRB has increased and the vibration period has decreased. The period ratios of the both X and V BRB scheme are less than 0.9 which meet the required condition of the torsional stiffness of the structure to be less than the lateral deformation stiffness.

The X direction stiffness (Figure 10.a) and Y direction stiffness (Figure 10.b) of the frame structure strengthened by $\mathrm{X}$ BRB configurations have greatly increased compared to other configurations.



(a)



(b)

Figure 10. Stiffness of original binding and strengthened building 


\section{Lateral Deformation Analysis}

The results show that the four BRB configurations were able to strengthen the building conforming to the Chinese design code.

Lateral displacement of the reinforced concrete frame structure strengthened by X BRB (Figures 11.a and 7.b) decreases the most compared to other configuration types. And single BRB strengthened frame has larger drift ratio which means that even though all the BRB reinforcement configurations conforms with the standard Single BRB has is not a good choice compared to others.

According to China's seismic code for buildings, the inter-story drift ratio of reinforced concrete frame structures should not be greater than 1/550 (about 0.00182) under frequent earthquakes. From the following Figures 11.c and 11.d, it can be seen that the drift ratio of the strengthened building meets the requirements. The drift ratio of the structure strengthened by $\mathrm{X}, \mathrm{V}$ and single BRB meets the requirements of the corresponding design specifications with the drift ratio for X BRB configuration being the smallest.

The stiffness of the frame reinforced by single brace configuration is smaller than others, that means that the single brace still have an advantage of little increase of the stiffness of the frame structure after reinforcement, say the mass of the strengthened structure compared to other configurations. For the tallest building where the top most stories are to be strengthened, this single BRB configuration may be beneficial in order to reduce the seismic effect of the strengthened structure.



(a)



(b) 




(c)

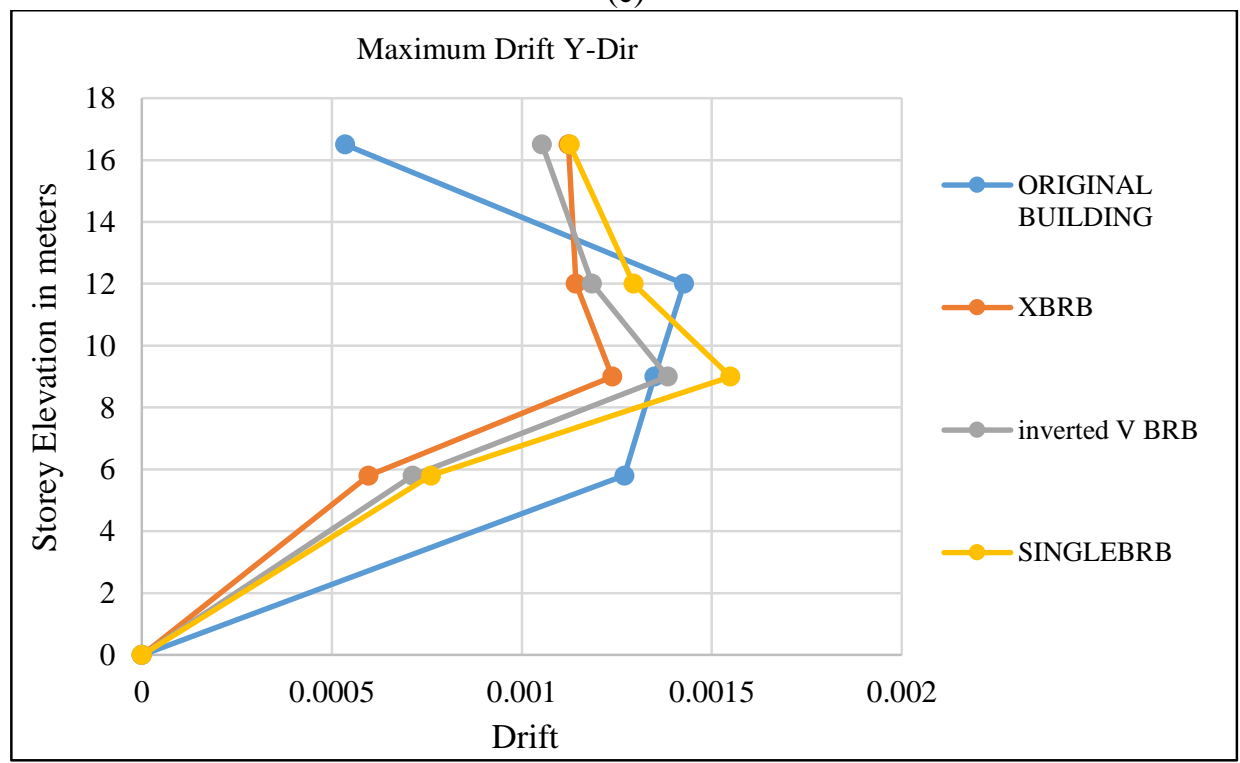

(d)

Figure 11. Maximum floor displacement and drift ratio of original binding and strengthened building

\subsection{Comparison between Ordinary Braces and Brb Strengthened R-C Frame Structure}

The researchers have demonstrated that lateral stiffness of frame structures can be improved by both ordinary braces and buckling restrained braces by setting them up to flexible stories. According to literatures, the following are differences between ordinary braces and BRB are highlighted as follows:

The bearing capacity of ordinary braces are determined by $N_{b}=\frac{\varphi A f}{1+0.35 \lambda_{n}}$.

And that of BRB is determined by $N_{b}=0.9 A f_{y}$.

With, $\varphi$ :stability coefficient of compression members; $A$ : The cross-section area of the brace; $\lambda_{n}$ : Adjusted slenderness ratio of the brace, $\lambda_{n}=\left(\frac{\lambda}{\pi}\right) \sqrt{\frac{f_{a y}}{E}} ; \lambda$ : Slenderness ratio of the brace; $f_{a y}$ : Yield strength of the steel, $E$ :elastic modulus of the steel.

Stability coefficient and slenderness ratio are essential in design of ordinary brace. According to GB50017-2003, for class a and class b Q235 steel, stability coefficient is less or equal to 1. Therefore, by comparing the two formulas of elastic bearing capacity, when the same steel material and same equivalent areas are considered for both ordinary and buckling restrained braces, the bearing capacity of buckling restrained brace will be larger than that of ordinary brace. By equalizing the two formulas for bearing capacity and assuming that the same material is used for both buckling restrained braces and $\mathrm{BRB}$ and taking the maximum value of stability coefficient, the required area of ordinary brace to the same bearing capacity as BRB is found to be 1.215 times that of BRB. 
In order to effectively compare seismic effect of the two types of braces, ordinary brace with the same configuration (X type), material and dimensions as BRB are installed at the same location in reinforced concrete frame structure as BRB.



(a)



(b)



(c) 




(d)

Figure 12. Stiffness of original binding and strengthened building by ordinary braces and BRB

From the results above (Figure 12), it can be seen that under action of small earthquakes the reinforced concrete frame with ordinary braces also satisfy the maximum drift ratio (Figure 12.c, d) and displacement (Figure 12.c, d) requirements for Chinese building seismic code.

The interlayer displacement of the frame structure strengthened by ordinary braces and BRB both conforms to the requirements of the specification, but the drift for structure strengthened by ordinary braces is larger than that of BRB brace (Figure 12.c, d). This is because the same cross-section areas are considered in this paper.

Because during small earthquakes, all braces are supposed to remain in elastic state, when the ordinary braces are designed according to the Chinese requirements, they will have bigger area than BRB and consequently high stiffness and this will result in smaller drift ratio and building horizontal displacement that that of BRB. Therefore, it can be recommended when the cost of the project is not a one of the selection criteria because the larger cross section area of ordinary brace will be costly.

When only rigidity and bearing capacity is to be improved, both BRB and ordinary brace can be used but the first can be economical and the last have better rigidity impact.

\subsection{Non-linear Time History Analysis of Strengthened Structure}

During elastic response spectrum analysis, the building response is assumed to respond in exclusively elastic manner, but because of the geometrical non linearity of the building, material non linearity of some structural members and possible seismic non linearity behaviors of some structural members, it is beneficial to perform nonlinear analysis.

In this paper nonlinear time history analysis of the strengthened building is analyzed under strong earthquakes.

\section{Selection of Seismic Waves}

According to the Code for Seismic Design of Buildings in China, the actual five strong earthquake records and two synthetic earthquakes are selected according to the types of building sites and design earthquakes grouping.

The spectral characteristics of the selected seismic waves were close as possible to the characteristic period of the building site, and the duration of the seismic waves selected conforming to the code.

The strengthened building was checked against strong earthquakes and the two types of braces are compared according to joint displacement, acceleration and base shear.

\section{Result Analysis}

The results show that under rare earthquakes, the base shear (Figure 13.c), peak acceleration (Figure 13.b) and peak displacement time history (Figure 13.a) of BRB structure are smaller than those of ordinary braces braces. The buckling restrained braces provide additional damping ratio for the structure, which reduces the displacement response of the structure under earthquakes and reduces the damage of the main structure caused by earthquakes. 




(a)



(b)



(c)

Figure 13. Time history results of Building strengthened by BRB and by ordinary braces 


\section{Conclusion}

The results of elastic response spectrum analysis show that under action of small earthquakes, both buckling restrained braces and ordinary braces can be used for strengthening of reinforced concrete frame structures according to Chinese requirement of seismic design, GB 50011-2010. This is due to the fact that ordinary braces will not buckle during small earthquakes. When both brace types are compared, ordinary braces will need to have the cross-section area that is bigger than that of BRB in order to have the same stiffness performance.

By performing nonlinear time history analysis, more ordinary braces fail due to excessive buckling but buckling restrained braces remain stable, this is shown by good performance of the frame structure restrained by buckling restrained braces compared to that of ordinary braces. One can ordinary brace is not safe alternative to be used in strengthening of concrete frame structures where strong earthquakes are expected.

Different configurations of BRB are studied. The results show that inverted $\mathrm{V}$ buckling restrained braces are better than V BRB, this is explained by the fact that for inverted V brace when one member is under tension another is under compression, and the force is directly transmitted to the column of the next lower floor. But for $\mathrm{V}$ brace, the load will be transmitted to the beam then to the column and this will affect the bearing capacity.

\section{Conflicts of Interest}

The authors declare no conflict of interest.

\section{References}

[1] Xie, Furen, Hongyan Zhang, and Yi Du. "The Recent Tectonic Stress Districts and Strong Earthquakes in China.” Rock Stress and Earthquakes (July 29, 2010): 35-40. doi:10.1201/9780415601658-7.

[2] Almeida, André, Ricardo Ferreira, Jorge M. Proença, and António S. Gago. "Seismic Retrofit of RC Building Structures with Buckling Restrained Braces.” Engineering Structures 130 (January 2017): 14-22. doi:10.1016/j.engstruct.2016.09.036.

[3] Li, Zhong-Jun. "Research on Steel Structures Design Method Using Energy Dissipation Brace for Story Lateral Ductility Ratio Control." Modeling and Computation in Engineering II (May 22, 2013): 141-147. doi:10.1201/b14896-22.

[4] Kumar, P.C. Ashwin, Dipti Ranjan Sahoo, and Abhay Kumar. "Seismic Response of Concentrically Braced Frames with Staggered Braces in Split-x Configurations.” Journal of Constructional Steel Research 142 (March 2018): 17-30. doi:10.1016/j.jcsr.2017.12.005.

[5] Kim, Jinkoo, and Hyunhoon Choi. "Behavior and Design of Structures with Buckling-Restrained Braces.” Engineering Structures 26, no. 6 (May 2004): 693-706. doi:10.1016/j.engstruct.2003.09.010.

[6] Wei, Hsi-Hsien, Igal M. Shohet, Mirosław J. Skibniewski, Stav Shapira, Robert Levy, Tsafrir Levi, Amos Salamon, and Moti Zohar. "Assessment of Casualty and Economic Losses from Earthquakes Using Semi-Empirical Model." Procedia Engineering 123 (2015): 599-605. doi:10.1016/j.proeng.2015.10.113.

[7] Nigg, Joanne M. “Anticipated Business Disruption Effects Due to Earthquake-Induced Lifeline Interruptions.” Post-Earthquake Rehabilitation and Reconstruction (1996): 47-57. doi:10.1016/b978-008042825-3/50008-9.

[8] Guo, Yan-Lin, Jing-Zhong Tong, Xiao-An Wang, and Peng Zhou. "Subassemblage Tests and Design of Steel Channels Assembled Buckling-Restrained Braces." Bulletin of Earthquake Engineering 16, no. 9 (February 22, 2018): 4191-4224. doi:10.1007/s10518-018-0337-5.

[9] Naghavi, Mohammad, Rohola Rahnavard, Robert J. Thomas, and Mohsen Malekinejad. "Numerical Evaluation of the Hysteretic Behavior of Concentrically Braced Frames and Buckling Restrained Brace Frame Systems." Journal of Building Engineering 22 (March 2019): 415-428. doi:10.1016/j.jobe.2018.12.023.

[10] Mazzolani, Federico M., Gaetano Della Corte, and Mario D’Aniello. "Experimental Analysis of Steel Dissipative Bracing Systems for Seismic Upgrading." Journal of Civil Engineering and Management 15, no. 1 (March 31, 2009): 7-19. doi:10.3846/1392-3730.2009.15.7-19.

[11] Kasai, Kazuhiko, Yoji Ooki, Shojiro Motoyui, Toru Takeuchi, and Eiji Sato. "E-Defense Tests on Full-Scale Steel Buildings: Part 1 - Experiments Using Dampers and Isolators." Structural Engineering Research Frontiers (October 10, 2007). doi:10.1061/40944(249)17.

[12] Guerrero, Hector, Tianjian Ji, J. Alberto Escobar, and Amador Teran-Gilmore. "Effects of Buckling-Restrained Braces on Reinforced Concrete Precast Models Subjected to Shaking Table Excitation.” Engineering Structures 163 (May 2018): 294-310. doi:10.1016/j.engstruct.2018.02.055. 
[13] Almeida, André, Ricardo Ferreira, Jorge M. Proença, and António S. Gago. "Seismic Retrofit of RC Building Structures with Buckling Restrained Braces.” Engineering Structures 130 (January 2017): 14-22. doi: 10.1016/j.engstruct.2016.09.036.

[14] Gao, Er Xin, and Yong Gui Wang. "Seismic Performance Study on Buckling-Restrained Brace." Applied Mechanics and Materials 353-356 (August 2013): 2101-2104. doi:10.4028/www.scientific.net/amm.353-356.2101.

[15] Ikhouane F., Rodellar J., "Variation of the Hysteresis Loop with the Bouc-Wen Model Parameters." Systems with Hysteresis (2007): 63-111. doi:10.1002/9780470513200.ch4.

[16] LI Hong-guang, HE Xu, MENG Guang, "Numerical Simulation for Dynamic Characteristics of Bouc-Wen Hysteretic System, "Journal of system simulation, vol. 16, pp. 2009-2011, (2016, Sep). (in Chinese).

[17] Tanuwidjaja, H.R., E.E. Tanuwidjaja, and G.K. Santoso. “An ETABS Study on Linearly Dynamic Analysis.” Proceedings of the Twelfth International Conference on Computational Structures Technology (2014). doi:10.4203/ccp.106.43. 